\title{
Immune responses to alglucosidase in infantile Pompe disease: recommendations from an Italian pediatric expert panel
}

\author{
Vincenza Gragnaniello ${ }^{1,2}$, Federica Deodato ${ }^{3}$, Serena Gasperini ${ }^{4}$, Maria Alice Donati ${ }^{5}$, Clementina Canessa ${ }^{6}$, \\ Simona Fecarotta ${ }^{2}$, Antonia Pascarella ${ }^{7}$, Giuseppe Spadaro ${ }^{2}$, Daniela Concolino ${ }^{8}$, Alberto Burlina ${ }^{1}$, \\ Giancarlo Parenti ${ }^{2,9}$, Pietro Strisciuglio ${ }^{2}$, Agata Fiumara ${ }^{10}$ and Roberto Della Casa ${ }^{2,11^{*}}$
}

\begin{abstract}
Background: Classic infantile onset of Pompe disease (c-IOPD) leads to hypotonia and hypertrophic cardiomyopathy within the first days to weeks of life and, without treatment, patients die of cardiorespiratory failure in their first 1-2years of life. Enzymatic replacement therapy (ERT) with alglucosidase alfa is the only available treatment, but adverse immune reactions can reduce ERT's effectiveness and safety. It is therefore very important to identify strategies to prevent and manage these complications. Several articles have been written on this disease over the last 10 years, but no univocal indications have been established.

Methods: Our study presents a review of the current literature on management of immune responses to ERT in c-IOPD as considered by an Italian study group of pediatric metabolists and immunologists in light of our shared patient experience.

Results: We summarize the protocols for the management of adverse reactions to ERT, analyzing their advantages and disadvantages, and provide expert recommendations for their optimal management, to the best of current knowledge. However, further studies are needed to improve actual management protocols, which still have several limitations.
\end{abstract}

Keywords: Pompe disease, CRIM status, Immune tolerance induction, Infusion associated reactions, Desensitization

\section{Introduction}

Pompe disease is an autosomal recessive lysosomal storage disorder in which deficiency of the acid $\alpha$-glucosidase (GAA) results in a build-up of glycogen in multiple tissues, particularly in the cardiac, skeletal and smooth muscle tissues [1]. Classic infantile onset of Pompe disease (c-IOPD), its most severe form, presents in the first days to weeks of life with hypotonia and hypertrophic cardiomyopathy. Without treatment, patients die of

\footnotetext{
*Correspondence: roberto.dellacasa@unina.it

${ }^{11}$ Dipartimento Materno Infantile, A.O. San Pio, Benevento, Italy

Full list of author information is available at the end of the article
}

cardiorespiratory failure within the first 1-2 years of life [2-4]. Enzymatic replacement therapy (ERT) with alglucosidase alfa (rh-GAA) is the only known treatment available [5]. Recommended dosage is $20 \mathrm{mg} / \mathrm{kg}$ every other week, although recent studies have reported that patients receiving up to $40 \mathrm{mg} / \mathrm{kg} /$ week have better outcomes [6-8]. ERT has been shown to improve ventilatorfree and overall survival as well as cardiomyopathy and motor functions [9-11]. However, immune reactions can reduce ERT's effectiveness and safety, thereby raising an important issue $[12,13]$.

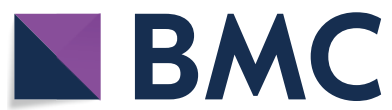

(c) The Author(s) 2022. Open Access This article is licensed under a Creative Commons Attribution 4.0 International License, which permits use, sharing, adaptation, distribution and reproduction in any medium or format, as long as you give appropriate credit to the original author(s) and the source, provide a link to the Creative Commons licence, and indicate if changes were made. The images or other third party material in this article are included in the article's Creative Commons licence, unless indicated otherwise in a credit line to the material. If material is not included in the article's Creative Commons licence and your intended use is not permitted by statutory regulation or exceeds the permitted use, you will need to obtain permission directly from the copyright holder. To view a copy of this licence, visit http://creativecommons.org/licenses/by/4.0/. The Creative Commons Public Domain Dedication waiver (http://creativeco mmons.org/publicdomain/zero/1.0/) applies to the data made available in this article, unless otherwise stated in a credit line to the data. 


\section{Materials and methods}

An Italian Pediatric study group on immune response to ERT in patients with Pompe disease consisting of pediatric metabolists and immunologists was established in December 2018 under the patronage of the Italian Society for Metabolic Diseases and Neonatal Screening (SIMMESN). The group's overall objectives were to assess the impact of immune reactions to ERT as measured by efficacy and safety and provide an expert panel consensus on the modalities, risks and benefits of immunomodulating and desensitizing therapy, particularly in patients with c-IOPD. We analyzed studies published from 2000 to 2021. They were identified by searching Pubmed, Medline and Embase, using the search terms "Pompe disease AND immune response", "Pompe disease AND immunomodulation", "Pompe disease AND hypersensitivity reactions", "Pompe disease AND desensitization". The literature search was supplemented by reviewing relevant citations in the in initial article identified. We screened title/abstract, reviewed full texts and extracted data. Exclusion criteria were studies published in language other than English, unpublished studies and abstracts. This study is a summary of the evidence present in the literature as a basis of discussion based upon direct patient experience concluding with expert opinions and recommendations for the optimal management of IOPD patients.

\section{Results and discussion}

\section{Types of immune reactions to ERT}

Two types of immune reactions against ERT have been reported: 1) infusion associated reactions (IARs) including hypersensitivity responses with or without increase of specific immunoglobulin E (IgE) and 2) development of specific immunoglobulin G (IgG) which reduces treatment efficacy by way of two different mechanisms: a) uptake of the administered enzyme in Fc receptor expressing cells such as monocytes and macrophages (binding, non-neutralizing antibodies) and b) targeting functional or catalytic domains (neutralizing antibodies) of the replaced enzyme $[12,14]$.

Antibodies and antigens can also form immune complexes and trigger a cascade of adverse events [15]. In addition to an antibody response, ERT has also been shown to induce a $\mathrm{T}$ cell response [16].

Based on anti-rhGAA IgG antibody titers, patients are classified into 3 groups [17]:

- HSAT (high and sustained antibody titer): $\geq 51,200$ on $\geq 2$ occasions at or beyond 6 months on ERT

- SIT (sustained intermediate titer): $\quad \geq 12,800$ and $<51,200$ within the first year of ERT
- LT (low titer): < 6400 within the first year of ERT.

HSAT is closely associated with clinical decline [18]. Moreover, there is evidence that antibodies levels $\geq 12,800$ (lower range of SIT) over a certain period of time also reduce the enzyme's efficacy [5]. It appears that the persistence of sustained titers for a long period of time, rather than the absolute values of the titers, impairs the ERT efficacy and thus the clinical outcome [19]. Approximately $90 \%$ of IOPD patients treated with alglucosidase alfa develop IgG antibodies [5, 20], with a large majority developing immunological tolerance with continued treatment $[18,21]$. Most pediatric patients develop antibodies in the first 3 months of therapy, but this is not always the case [11]. Sometimes, antibodies become positive or peak several years after beginning ERT [22].

Statement \#1: On the basis of literature data and the personal experience of the authors, the Expert Panel suggests IgG assay at time 0 , monthly for 12 months, and every 3 months thereafter. After many years, IgG assay is indicated only in cases of clinical deterioration and always in cases of adverse reactions [23]. If positive, the sample must be further tested for neutralizing antibodies [12]. IgE is measured in the setting of a hypersensitivity reaction and is not routinely tested [24]. Assays available include non-standard laboratory tests and are carried out by specialized labs or by the drug manufacturer's producer.

\section{Risk factors for immunogenicity: CRIM (cross reactive immunological material) status}

Several factors need to be considered in assessing immunogenicity risk. Index signs of the severity of the clinical phenotype such as early onset of symptoms, severe cardiomyopathy, and residual enzyme activity $(<1 \%)$, have been considered by some authors to be risk factors for the development of a high antibody titer, while there seems to be no link with ERT dose, infusion rate, and age at the time of therapy inception, contrary to what was assumed in the past $[12,22]$. The most important factor indicated appears to be CRIM status [20, 25, 26].

Patients with no detectable GAA protein are classified as CRIM negative $(\mathrm{CN})$, so that their immune system fails to tolerate ERT and recognizes it as foreign (about 30\% of patients with c-IOPD). Patients with some residual GAA protein (active or inactive forms) are classified as CRIM positive (CP), and usually do not mount an immune response or else mount a transient low titer response [20, 25]. Previous studies have demonstrated that in CRIM negative patients antibody titers were higher, seroconversion occurred earlier (by 4 weeks), titers were sustained at 
high levels, and neutralizing antibodies often developed. Conversely, CRIM positive patients showed a variable time to seroconversion (4-64weeks, median 8weeks) with either no antibody response or a non-neutralizing antibody response with a low peak titer that diminished with continued therapy [20,26].

Serotiter levels play a role in the clinical decline of the CRIM negative patients. Kishnani et al. reported that both CRIM positive and CRIM negative groups showed similar cardiological status (left ventricular mass index), gross motor development, and biomarker levels (eg tetrasaccharide) at baseline. After 26 weeks of ERT both groups showed improvement but at 52 weeks, CRIM positive patients demonstrated additional improvement, while the CRIM negative group worsened in correlation with the increased and persistent antibody response. By 27.1 months of age, all CRIM negative patients were deceased or on ventilators compared to $19 \%$ of the CRIM positive patients [20]. Similar results were reported by Van Gelder et al. [27].

A previous Italian experience on 28 patients, followed for a median period of 6 years, also demonstrated that, compared to CRIM negative, CRIM positive patients showed a better outcome. In particular, the risk of death in CRIM positive patients was $1 / 4$ and ventilator free survival risk was $1 / 5$ compared to CRIM negative patients. CRIM positive patients also showed improved motor and cardiac outcomes. Of note, data concerning the titers of anti-rhGAA antibodies were available in 13 patients $(7$ CRIM positive, 5 CRIM negative, 1 unknown) and all CRIM positive patients have no antibodies or were LT, while all CRIM negative patients were SIT or HSAT [28].

Immune tolerance induction (ITI) protocols can be used for prophylaxis, to preempt immune response in ERT naive patients (prophylactic approach), and for therapy, to decrease existing antibodies in ERT treated patients with previously established immune responses. For this purpose, it is important to know CRIM status before starting ERT. The gold standard to determining CRIM status is the western blot analysis of skin fibroblast lysates. However, skin biopsies are invasive and require several weeks. A more rapid method for determining
CRIM status using western blot analysis of blood mononuclear cells (PBMCs) was successfully tested on a small number of patients $(n=8)$ [29] but its sensitivity was assessed at only around $82 \%$ in a subsequent study including 33 patients [30]. CRIM status can also be predicted based on GAA gene mutations in more than $90 \%$ of patients. The types of mutations in Pompe disease are shown in Table 1 [31, 32]. If, based on the mutation, CRIM status is not already foreseen, a western blot on fibroblasts should be performed [31].

Statement \#2: Before starting ERT in a c-IOPD patient, it is essential to determine the CRIM status. The protocol recommended by the Expert panel is shown in Fig. 1. This protocol provides information useful for therapeutic decisions in about 1 week.

\section{Prophylaxis protocols in CRIM negative patients}

Most CRIM negative patients develop HSAT, but limited information is available to accurately predict those who are least likely to develop it. Accordingly, a risk-benefit ratio supports initiating an immunotolerance protocol at the time of ERT inception. Advantages of preemptive immunotolerance induction are exposure to fewer drugs, shorter duration of therapy and improved clinical outcomes by preventing prolonged exposure to HSAT [33]. Several protocols have been used as described below and summarized in Table 2.

1) Rituximab (RTX) + methotrexate (MTX) + intravenous immunoglobulins (IVIG) (short course, 5 weeks)

Banugaria et al. first reported this protocol in 7 CRIM negative patients. Four patients never seroconverted, one remained with a LT of antibodies, while other two patients had a peak of 1:6400 and receiving a second course of the same ITI regimen. In fact, their protocol provided that patients with antibody titers of $\geq 6400$ at 2 or more time-points after CD19+ B cell recovery at 5 months were administered another cycle of the ITI regimen with or without a plasma cell targeting agent [23].

Table 1 Types of mutations in Pompe disease [31]

\begin{tabular}{|c|c|c|}
\hline Type of mutation & Effect & Exceptions \\
\hline $\begin{array}{l}\text { Nonsense, frameshift, multiple exon deletion } \\
\text { mutations }\end{array}$ & Two alleles: CRIM negative & $\begin{array}{l}\text {-Premature termination codon in the last exon or up to above } \\
50 \text { nucleotides from the } 3^{\prime} \text { end of the penultimate exon } \\
\text { - In frame deletion }\end{array}$ \\
\hline Missense mutation & At least one: CRIM positive & Point mutation that abolished the initiator methionine codon \\
\hline Splicing mutation (about 15\%) & Difficult to predict & - \\
\hline
\end{tabular}




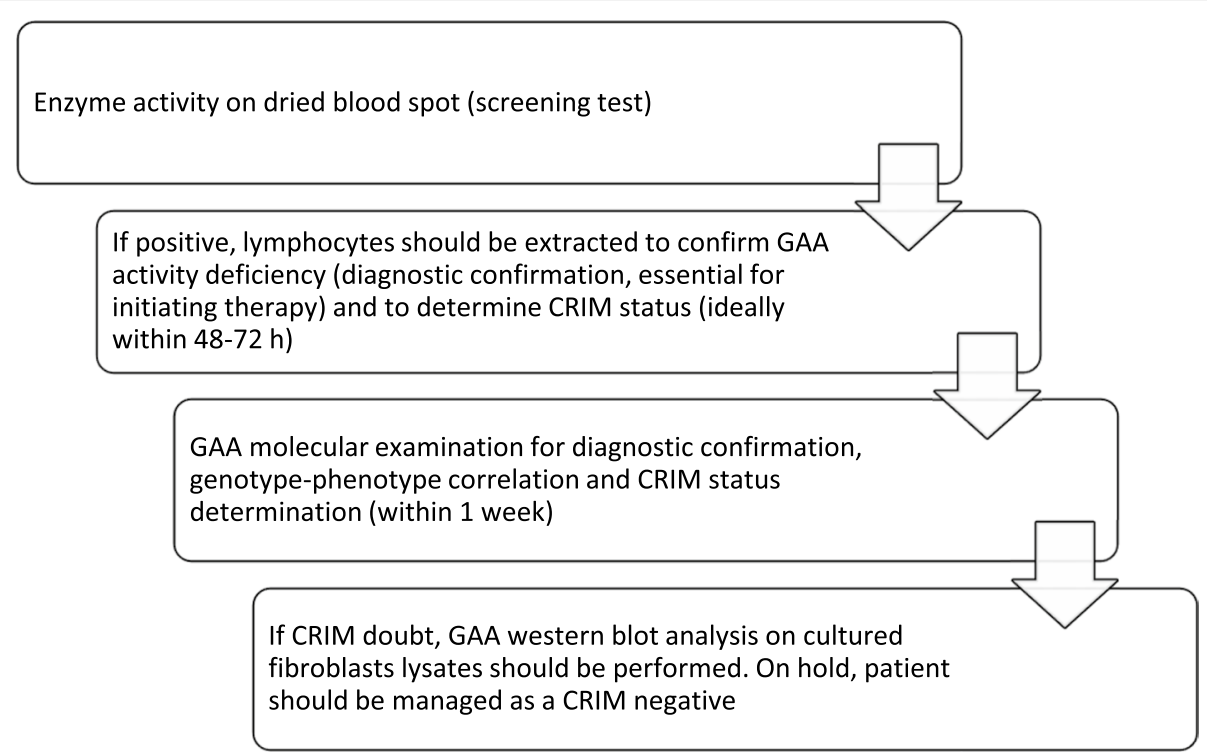

Fig. 1 Approach to a child with suspected Pompe disease

Table 2 Prophylaxis protocols in naive patients

\section{CRIM negative patients}

$R T X+M T X+I V I G\left(\right.$ short course, 5 weeks) $[23,34,35]^{\mathrm{a}}$

- RTX $375 \mathrm{mg} / \mathrm{m} 2$ IV (or if body surface area $<0.5 \mathrm{~m}^{2}=12.5 \mathrm{mg} / \mathrm{kg}$ ) weekly four times, the first dose given 1 day before the first ERT administration.

- MTX $0.4 \mathrm{mg} / \mathrm{kg}$ sc/orally, 3 doses per week or MTX $1 \mathrm{mg} / \mathrm{kg} /$ weekly [36] for almost 3 weeks with or without IVIG 400-500 mg/kg monthly for a period of 5-6 months (until B cell levels had reached normal values for age)

RTX+ sirolimus or mycophenolate + IVIG [37]

- RTX IV: $750 \mathrm{mg} / \mathrm{m}^{2}$ 10-14 days apart or $375 \mathrm{mg} / \mathrm{m}^{2}$ per week for 3 weeks (dosed depending on the infant's clinical status and ability to tolerate IV fluids).

- Sirolimus $0.6-1 \mathrm{mg} / \mathrm{m}^{2}$ per day adjusted to maintain serum level of $3-7 \mathrm{ng} / \mathrm{ml}$ or mycophenolate $300 \mathrm{mg} / \mathrm{m}^{2}$ per day.

- IVIG 500-1000 mg/kg adjusted to maintain serum IgG levels of 700-1000 mg/dl.

- After an initial pre-ERT course of immunomodulation (3 weeks), ERT is initiated alongside maintenance with every 12-week RTX, daily sirolimus or mycophenolate mofetil and monthly IVIG administration.

\section{CRIM positive patients}

Low-dose MTX [17]

- MTX at $0.4 \mathrm{mg} / \mathrm{kg}$ body weight is administered on the day of ERT infusion subcutaneously ( $15 \mathrm{~min}$ before or orally $1 \mathrm{~h}$ before if subcutaneous administration is not possible) and again on the following 2 days with the first 3 ERT infusions.

$R T X+M T X+I V I G$ (short course, 5 weeks) [38]

- See above (CRIM negative patients)

CRIM cross-reactive immunologic material, ERT enzyme replacement therapy, RTX rituximab, MTX methotrexate, IVIG intravenous immunoglobulins

${ }^{\text {a }}$ Because RTX is a monoclonal antibody, administering IVIG prior to RTX may saturate the FcRn receptor, thereby precluding recycling of RTX and its sustained activity [39] and therefore administration of RTX is recommended prior to IVIG [34]

Successively, Kazi et al. reported the same protocol in 19 CRIM negative patients. 15 out of 19 patients (79\%) either did not develop rhGAA IgG antibodies $(n=8$, never in ERT monotherapy group) or maintained low titers $(\leq 6400)$ even after B lymphocytes reappeared. Four patients required further cycles of ITI (1 HSAT, 3 SIT) [34]. This may be due to a Fcy receptor polymorphism which reduces the efficacy of rituximab [40]. No significant difference in baseline characteristics was noted between patients who had broken tolerance to the ERT compared with those who had maintained low/ no titers. Patients who had been undergoing immunomodulation regimen, when compared to those on ERT monotherapy $(n=10)$, showed improved overall and ventilator-free survival, improved cardiomyopathy, motor function and feeding (like CRIM positive survivors on 
ERT), evident after the first 6 months. Conversely, during the same period of time, the monotherapy group worsened because of development of antibodies within the HSAT range. Although serious infections were noted in 4 patients, no immunomodulation regimen was witheld due to safety concerns. Titer against routine vaccines was performed after B cell recovery in 4 patients, which demonstrated the ability to mount a humoral response to other antigens, although not in all patients nor for all antigens. This data has been confirmed by other authors as well [22, 41]. Poelman et al. used the same protocol, but with a different dosage of methotrexate (Table 2) on 1 CRIM negative and 2 CRIM positive patients [36]. However, the immune regimen failed to induce immune tolerance: 2 patients developed an high and sustained titer (1 CRIM negative and 1 CRIM positive) and 1 CRIM positive patient developed a titer of 1:6250. More recently, $\mathrm{Li}$ et al. reviewed a cohort of CRIM negative patients, among which 20 were immunomodulated before starting ERT. All remained immunotolerant, 13 no seroconverted, 7 developed LT. Compared to historical cohort treated with ERT monotherapy $(n=10)$, of whom median peak titer was 204,800 (range 25,600-1,638,400), patients treated with ERT + ITI had significantly lower median peak titer of $0(n=20,0-51,200)$. Surprisingly, within the cohort treated with ERT + ITI, although early treated patients $(\leq 4$ weeks) showed a better outcome than late treated, the number of immunotolerant patients (titre $\leq 6400$ ) did not differ significantly between these groups. However, early treated patients were significantly more likely to remain seronegative than late treated patients [42].

2) Rituximab (RTX) + sirolimus or mycophenolate + intravenous immunoglobulins (IVIG)

Elder et al. described treatment of 5 infantile onset patients (4 CRIM negatives, 1 CRIM positive) using this protocol [37]. It prevented antibody formation with improved outcomes and no adverse events except in 1 CRIM negative patient (who had not received maintenance rituximab, but only mycophenolate) who developed HSAT and subsequent clinical decline. One limitation is that this protocol delays initiation of ERT for 3 weeks, which can lead to irreversible muscle damage.

\section{Prophylaxis protocols in CRIM positive patients}

A subset of CRIM positive patients (about 40\%) develop HSAT. These patients are defined as high-titer CRIM positive (HTCP patients) and have a similar pattern of antibody response and clinical decline as CRIM negative patients. The most marked difference between CRIM positive HSAT and CRIM negative patients regards the development of neutralizing antibodies which seem to be a common occurrence in CRIM negative groups. The basis for this finding is not clear; however high titers of binding antibodies such as those present in HTCP patients may also abrogate product efficacy by several mechanisms. HCTP patients have similarly poor outcomes compared to CRIM negative patients $[18,43]$. The main characteristics of immune responses in different patient groups is shown in Table 3.

Kazi et al. used a transient low dose methotrexate protocol to prevent the developing of antibodies in naive CRIM positive patients (Table 2) [17]. In a study on 14 patients, $2(14.2 \%)$ developed titers in the HSAT or SIT range versus $32.4 \%$ in the comparison group $(n=37)$.

A more recent work of the same group retrospectively studied the effects of a more complex protocol (short-course of rituximab, methotrexate, and/or IVIG, as described for CRIM negative patients, see above) in a cohort of 9 ERT-naive CRIM positive patients. None developed SIT or HSAT, after a median timepoint following ERT initiation of 104 weeks [38].

Statement \#3: On the basis of the risk-benefit ratio reported in the literature and discussion of the personal experiences of the authors, the Expert panel believes that in CRIM negative patients the first reported regimen above (RTX + MTX + IVIG - short course, 5 weeks) has shown to have the best success in achieving long-term immune tolerance without longterm toxicity and delay in ERT initiation. In CRIM positive patients, it is possible to use the same protocol or a low-dose methotrexate protocol, because the literature data are not conclusive. Authors believe that, based on the clinical condition of the patient and the presence of other risk factor (GAA variants already reported in patients who developed SIT or HSAT, older siblings that developed SIT or HSAT, etc.), an individualized evaluation of the risk-benefit ratio is needed. In case of doubt of CRIM status, the authors agree that the patient should be treated as a CRIM negative patient until the result of the western blot analysis on fibroblasts is available.

Table 3 Main characteristics of immune responses in different patient groups [18]

\begin{tabular}{llll}
\hline & CN & CP HSAT & CP LT \\
\hline Median time to seroconversion & 4 weeks & 4 weeks & 8weeks \\
Median titer at 26 weeks & $1: 51,200$ & $1: 51200$ & $1: 400$ \\
Median titer at 52 weeks & $1: 153,600$ & $1: 51,200$ & $1: 200$ \\
Median peak & $1: 204,800$ & $1: 204,800$ & $1: 800$ \\
\hline
\end{tabular}

CN CRIM negative, CP CRIM positive, HSAT high sustained antibody titer, $L T$ low titer 


\section{Genetic predisposition to HSAT risk}

An important focus is early identification of patients who are at the highest risk of developing HSAT in order to adopt more appropriate immunomodulatory regimens [18]. GAA variants alone are not reliable to predict the development of anti-ERT antibody, both in CRIM positive and in CRIM negative patients [13, 23, 25].

De Groot et al. developed an individualized $\mathrm{T}$ cell epitope measure (iTEM) approach for the prediction of anti-drug antibodies development. For each patient, a sum of the predicted individual $\mathrm{T}$ cell epitope content in rhGAA (based on the HLA-DRB1 alleles and compared to their own mutate native GAA) was calculated to determine the individual risk of developing anti-drug antibodies [44]. In their study all 5 CRIM negative subjects had a highly elevated iTEM score and, as predicted, all had high anti-drug antibody responses to ERT. Among 19 CRIM positive patients, $8 / 10$ with high anti-drug antibodies and 7/9 with low anti-drug antibodies were correctly identified, with an overall agreement with high anti-drug antibodies of $88 \%$ (sensitivity $87 \%$, specificity $89 \%$ ). This approach personalizes risk assessment in IOPD and may be useful in identifying CRIM positive patients at high risk for HSAT/SIT development who would benefit from immunomodulation. It could be very useful in the next few years.

\section{Immune tolerance induction in patients who developed antibodies during ERT}

The elimination of anti-ERT antibodies, particularly those within the range of HSAT, has been challenging as patients require prolonged and higher intensity immune modulation and sometimes immune suppression is unsuccessful [13, 45]. Furthermore, since antibodies take weeks to decline to clinically insignificant levels, the enzyme is less likely to have an effect during this period of HSAT and the disease continues to progress [40]. The protocols used are summarized in Table 4 .

1) Rituximab (RTX), methotrexate (MTX), and intravenous immunoglobuline (IVIG)

This protocol was shown to be effective by Mendelsohn et al. in 1 CRIM negative patient with titer 1:1600 [46], Messinger et al. in 2 CRIM negative patients with titers 1:1600 and 1:12,800 respectively [35], Markic et al. in 1 CRIM positive patient with titer 1:6400 [49], and Blasco-Alonso et al. in 1 CRIM negative patients with titer 1:32000 [50], but it often required prolonged drug administration. Moreover, the success of eliminating anti-drug antibodies is demonstrated only in patients with non-HSAT titers. It is possible that patients with HSAT may not respond to this regimen due to the use of drugs that do not target antibody producing plasma cells [43].

2) Bortezomib, rituximab (RTX), methotrexate (MTX), and intravenous immunoglobuline (IVIG)

To eliminate long-memory plasma cells, especially in HSAT patients, some authors added bortezomib, a plasma cell-targeting agent [23, 47]. These authors described 1 CRIM negative and 2 CRIM positive HSAT who after treatment showed a rapid sustained decline of the antibody titer associated with clinical improvement and reduction of urinary tetrasaccharide levels without serious adverse events or infections. Similar results were obtained by Stenger et al. in 1 CRIM positive patient with HSAT [41]. Conversely, Owens et al. reported 2 patients (1 CRIM positive and 1 CRIM negative) in whom

Table 4 Immune-tolerance induction protocols in patients who developed antibodies during ERT

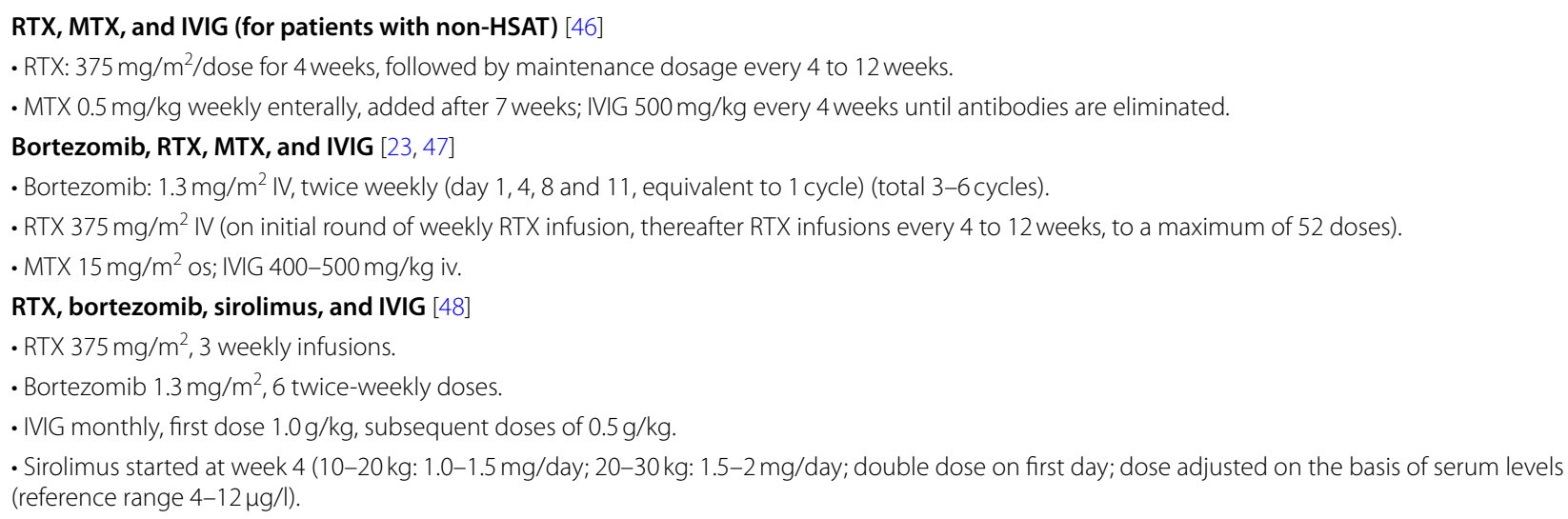


bortezomib failed to eliminate HSAT despite the reduction in IgG antibody titer. This could be explained by the administration of a limited number of bortezomib cycles and the already advanced disease progression at the time of bortezomib initiation [51].

3) Rituximab (RTX), bortezomib, rapamycin, and intravenous immunoglobulins (IVIG)

Poelman et al. described this protocol in two CRIM negative and 1 CRIM positive patients with HSAT. The protocol did not eliminate anti-ERT antibody titers although the titers decreased and the neutralizing effects and infusion-associated reactions were no longer present. None of the patients experienced a serious adverse event [48].

Anecdotal reports have been made on the use of plasma exchange to remove pathogenic antibodies and immune complexes from plasma and high-dose IVIG $(1-3 \mathrm{~g} / \mathrm{kg} /$ week) in patients with adverse reactions to other drugs, but with modest results, and in patients with low antibody titers involving, in the case of plasma exchange, additional risks related to the procedure [52, 53].

Lastly, ERT dosage can have a role in determining the efficacy of the drug in patients with an antibody response: with a higher dosage $(40 \mathrm{mg} / \mathrm{kg} /$ week $)$, more antibody-free ERT should be available and the neutralizing effects of the same titer are likely to be less severe than in patients receiving $20 \mathrm{mg} / \mathrm{kg}$ every other week. For example, van Gelder et al. calculated that an ELISA titer of $1: 156,250$ may bind as much as $54 \%$ of the administered enzyme at a dosage of $20 \mathrm{mg} / \mathrm{kg}$ (about $10 \mathrm{mg} / \mathrm{kg}$ ) [27]. Theoretically, if a similar amount is bound upon administration of $40 \mathrm{mg} / \mathrm{kg}$, about $30 \mathrm{mg} / \mathrm{kg}$ would still be available for uptake in target tissues [27, 48]. Recently, an observational study of the European Consortium project group on $124 \mathrm{c}$-IOPD concluded that ERT dosage of $40 \mathrm{mg} / \mathrm{kg} /$ week significantly improves survival compared to standard dosage $(20 \mathrm{mg} / \mathrm{kg}$ every other week) [54]. Further studies on patients with positive antibodies are needed.

Statement \#4: The Expert Panel believes that the best regimen in case of high antibody titer is comprised of the use of Bortezomib, Rituximab, Methotrexate and intravenous immunoglobulins. Early initiation after antibodies appear and prolonged therapy is important. Although antibody titers $>51,200$ should be considered carefully, there is no antibody titer threshold to be treated. It is indeed important to consider the overall clinical picture, especially if there is clinical decline with persistent or increasing titer. In patients with sustained low titers, a dose increase may be beneficial. Furthermore, in patients who are already critically ill with a negative prognosis (e.g. artificially ventilated), discussion with parents is necessary to assess the benefit-risk of the immunotolerance induction. Additional research will be needed to establish the optimal means of tapering the maintenance regimen.

\section{Mechanism and adverse reactions}

The immunomodulation regimens target immune cells at different levels including elimination of $\mathrm{B}$ cells, $\mathrm{T}$ cells, plasma cells and induction of GAA-specific $B_{\text {reg }}$ and $T_{\text {reg }}$. Table 5 summarizes the mechanisms of immune tolerance and potential adverse events of pharmaceutical agents that are commonly used. It should be noted that the duration of rituximab-induced immunosuppression is about 5 months (based on the half-life of the drug) and the increase in CD19 can be associated with increased specific antibody response [23].

Statement \#5: On the basis of available literature and accumulated personal experiences, the Expert Panel recommends, before starting immunomodulation, performing the following tests: blood cells count, C-reactive protein, immunoglobulins (IgA, IgG and IgM), and flow-cytometry (B and T cells) to have a baseline assessment and exclude infections. To verify the effect of rituximab on B lymphocytes, we suggest performing flow-cytometry to monitor B cell recovery (CD19\% and CD20\%) and total serum immunoglobulins (IgA, IgM, IgG) weekly for 2 weeks (before the next rituximab dose), and monthly thereafter (before each Ig infusion) until full B cell recovery. To monitor the side effects of methotrexate, it is useful to monitor blood counts, AST and ALT levels, and creatinine. Neutropenia and increased AST and ALT levels or fever may necessitate temporary discontinuation. Folic acid supplementation can be considered to prevent or treat MTX toxicity.

Immunomodulation regimens are relatively nonantigen specific and have the potential to cause generalized immune suppression with a risk of infection, also with opportunistic pathogens, and malignancy [23, 37]. Patients with Pompe disease are already susceptible to lung involvement with higher risk of infections. Surprisingly, very few reports of severe life-threatening infections have been reported. This may be due to the use of intravenous immunoglobulins [23] and to the improvement of the underlying disease [12]. There are anecdotal reports of the use of preventive antibiotic therapy (e.g. azithromycin) during immunomodulation regimens [48]. Vaccination response might be diminished during immunotolerance induction and during the following 6 months 
Table 5 Drugs commonly used for immune toleration

\begin{tabular}{|c|c|c|}
\hline Drug & Mechanism & Adverse events \\
\hline Bortezomib & $\begin{array}{l}\text { Proteasome inhibition: blocks protein recycle and production } \\
\text { of antibodies in plasma cells }{ }^{\mathrm{a}}[55,56]\end{array}$ & $\begin{array}{l}\text { Peripheral neuropathy, anemia, neutropenia, thrombocyto- } \\
\text { penia, gastrointestinal and cardiac side effects [23] }\end{array}$ \\
\hline IVIG & $\begin{array}{l}\text { Binding to the neonatal Fc receptor (FCRn) which is responsi- } \\
\text { ble for recycling of antibodies thus downregulating antibody } \\
\text { responses }[53,57,58] \\
\text { Passive immunity during the period of immune suppression } \\
\text { due to other drugs (specially rituximab) }[23]\end{array}$ & Infusion-associated reactions [59] \\
\hline Methotrexate & $\begin{array}{l}\text { Inhibits folic acid metabolism (which blocks de novo DNA } \\
\text { synthesis), thus eliminating dividing B and T cells. } \\
\text { Low dose: Induces regulatory B cells rather than cell depletion } \\
{[60,61]}\end{array}$ & $\begin{array}{l}\text { Bone marrow and gastrointestinal toxicities, rarely acute } \\
\text { pneumonitis, pulmonary fibrosis and renal function impair- } \\
\text { ment }[12,62]\end{array}$ \\
\hline Mycophenolate mofetil & $\begin{array}{l}\text { Inhibition of proliferative responses of } T \text { and } B \text { lymphocytes } \\
\text { [12] }\end{array}$ & Leukopenia, anemia and thrombocytopenia \\
\hline Rapamycin & $\begin{array}{l}\text { Mammalian target of rapamycin (mTOR), which inhibits cell } \\
\text { survival and proliferation of B and T lymphocytes, but selec- } \\
\text { tively promotes regulatory } T-\text { Treg }- \text { cells }^{b}[63-67]\end{array}$ & \\
\hline Rituximab & $\begin{array}{l}\text { Monoclonal antibody against CD20 molecule expressed on } \\
\text { B cells [12] }\end{array}$ & $\begin{array}{l}\text { Infusion-associated reactions, lymphocytopenia, progressive } \\
\text { multifocal leukoencephalopathy [62] }\end{array}$ \\
\hline
\end{tabular}

a In muscle, the ubiquitin-proteasome system is believed to degrade contractile skeletal muscle proteins and may play a critical role in muscle wasting [23]

${ }^{b}$ May have an impact on glycogen storage in muscle by influencing the mTor pathway and inhibiting glycogen storage [68]

[23]. There is little documented experience on the longterm effects of immune modulating therapies in children over time and long-term assessment is needed.

Statement \#6: Our Expert Panel recommends observing adequate hygiene rules during the immunomodulation regimen and to avoid closed and crowded places and sources of infection. The authors believe that preventive antibiotic therapy is not routinely required. In cases of fever, prompt medical evaluation is recommended, and in cases of signs or symptoms suggestive of bacterial infection, antibiotic therapy must be started promptly. Live vaccines should be avoided while on treatment and immediately following treatment until there is full B cell recovery. Non-live vaccines can be given according to the vaccination schedule, but vaccination response should be monitored even after B cell recovery and, in case of inadequate response, additional vaccine boosts should be considered. During flu season, it is recommended to vaccinate all close contacts of the subject.

\section{Hypersensitivity reactions to ERT}

About half of patients with Pompe disease experience infusion associated reactions which can involve a wide range of clinical symptoms especially cardiac, respiratory, cutaneous and/or gastrointestinal manifestations. Approximately $1 \%$ of patients develop anaphylactic shock and/or cardiac arrest that requires life-support measures, while $5-14 \%$ of patients develop significant allergic reactions that involve at least 2 or 3 body systems [5]. These can appear at various times, even years after the start of the ERT [27]. Risk factors include the presence of IgE (which does not seem to correlate with IgG), acute illness at the time of the infusion, or a very high-rate infusion regimen, while there does not seem to be a correlation with dosage or IgG levels $[22,69,70]$. In a previous Italian observational study, among 128 patients eight experienced hypersensitivity reactions (6.25\%) [28].

Hypersensitivity reactions can be classified as allergic and non-allergic. Allergic hypersensitivity, either IgE- or non-IgE mediated, is antigen specific. In this case skin tests and intradermal tests are usually positive and tryptase increases within $1 \mathrm{~h}$ after clinical reaction (peaks at $60-90 \mathrm{~min}$ after the onset of symptoms and remain elevated for up to $5 \mathrm{~h}$ ), as the reaction is mast cell/basophil mediated [71-73]. A non-allergic reaction (more frequent) is not antigen specific. An immunologic pathogenic mechanism has not been demonstrated, but may be related to mechanisms of complement activation, cytokine release, and direct mast cell stimulation [5].

As infusion-associated reactions of various mechanisms have similar presentation, clinicians are unable to use clinical history to predict these events and guide management [74]. After a potential hypersensitivity reaction has been identified, three approaches are possible: standard prevention and management, immunomodulation, and desensitization [75].

Standard prevention and management include: slowing down or interrupting infusion and then restored it at the last safe rate (then, gradually increasing dose, 
rate, and concentration), monitoring of vital signs, symptom-specific medical intervention (e.g. antipyretics, antihistamines, corticosteroids, inhaled short-acting beta2-agonists if bronchoconstriction, epinephrine if anaphylaxis) and drawing blood for laboratory tests [3, 10, 11, 76-78]. After an adverse reaction, a premedication protocol can be applied. Most of the premedication protocols provide for the use of antihistamines, glucocorticoids, and antipyretics [79]. However, prophylactic antihistamines are not recommended in patients with a history of IgE positive hypersensitivity reactions, as this may mask early symptoms of a hypersensitivity reaction such as a cutaneous reaction [69]. Some authors have suggested the use of tranexamic acid $(500 \mathrm{mg} /$ day), especially in patients with angioedema or complementmediated infusion-associated reactions, since it inhibits plasmin activation of kallikrein and interrupts the kinin generating cycle [79]. A novel approach for IgE mediated anaphylaxis uses an IgE monoclonal antibody, namely omalizumab. One patient had been successfully treated with omalizumab, but he appeared to require its chronic administration to continue ERT. Interestingly, this patient, who was CRIM negative, also maintained a low IgG antibody titer suggesting that omalizumab, perhaps via signaling through the Fce receptor, had also limited development of the IgG response [80]. Nonetheless, further studies are needed.

Statement \#7: In patients at high risk (e.g. acute illness at the time of the infusion) ERT should be administered at a slower rate. After a reaction, slowing or interrupting infusion and supportive measures are recommended. It is useful to draw blood for analysis of IgE titer, tryptase and complement activation. Our Expert Panel believes that a routine premedication is not particularly useful, but after an infusion associated reaction a premedication with 4 drugs is recommended: antihistamines $(\mathrm{H} 2$ antagonist $+\mathrm{H} 1$ antagonist), unless specific IgE antibodies are present, glucocorticoids and tranexamic acid if angioedema or complement activation are present.

Some immunomodulation approaches, as those described above, have also demonstrated to alleviate hypersensitivity reactions, if it is sustained by an antibody response. Thus, they are a limited role in cases with positive anti-rhGAA antibodies. Moreover, these regimes result in significant risks and reappearance of antibodies following successful initial suppression has been reported $[13,78]$.

If these measures fail or are unapplicable, desensitization is strongly indicated. Desensitization is the induction of a temporary state of unresponsiveness to a compound responsible for a hypersensitivity reaction (IgE and
non-IgE mediated) by increasing sub-therapeutic doses over a short period of time until the total cumulative therapeutic dose is delivered. It is a high-risk procedure and should be used only in patients in whom there is no safe, effective alternative drug treatment (e.g. ERT in Pompe disease) and after careful risk-benefit analysis [72].

Infants with Pompe disease subject to a desensitization protocol require attention to special aspects such as the need for administration of a large amount of enzyme (compared to patients on ERT for other disorders), and the restricted amount of fluid intake allowed due to underlying cardiomyopathy [69]. Particular attention should be paid to patients at increased risk because of a comorbidity such as hemodynamically unstable patients, those with uncontrolled cardiac disease, or subjects who have experienced severe anaphylaxis. No specific guidelines yet exist. General rules are suggested by the "EAACI consensus statement on rapid desensitization for drug hypersensitivity" [61]. Any concomitant medication must be continued however drugs such as beta-blockers, which can interfere with the treatment of a severe hypersensitivity reaction, should be discontinued whenever possible. Generally it is preferable to use desensitization protocols after they have been successfully proven on at least 10 patients [61] although only a few Pompe patients having ERT with desensitization have been described.

To our knowledge, 10 cases ( 8 pediatric, 2 adults) affected by Pompe disease and subjected to desensitization protocol have been reported $[14,56,74,75,79$, 81, 82] (Table 6). Of note, recently Emecen Sanli et al. reported the first case of successful concomitant immunotolerance induction and desensitization protocol in a CRIM negative 7-month-old male patient, that have developed IARs and anti-rhGAA antibodies $(1: 12,800)$ [83].

Most of these protocols (6/10) administered a half dose $(10 \mathrm{mg} / \mathrm{kg})$ once a week. Only one patient was on a very low dose of ERT for a longer period (8weeks) [75]. Breakthrough reactions are drug hypersensitivity reactions that occur despite the desensitization procedure. These most often occur during the first course of desensitization [72]. Such reactions have been reported in 7 of 10 patients and were mild/moderate in 4 , while 3 patients experienced severe infusion-associated reactions including anaphylactic reactions requiring epinephrine injections in 2 cases (Table 6). After a breakthrough reaction, some authors did not modify the protocol, while others decelerated the dose escalation introducing intermediate dosing steps, or going back one or two steps, depending, however, on the severity of the reaction.

Statement \#8: If other measures fail, desensitization is recommended. The infusion should be carried out 


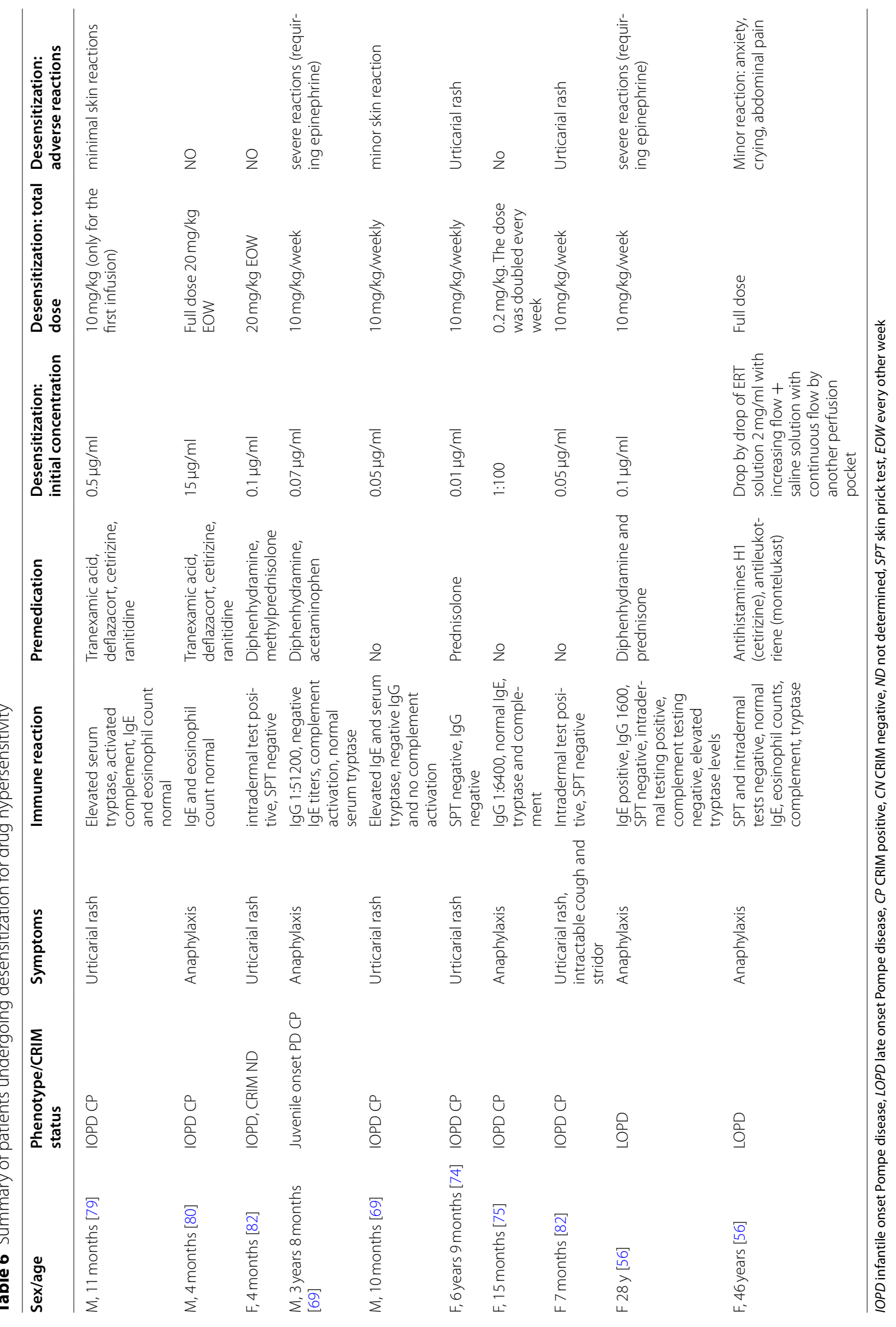


Table 7 Proposal of desensitisation protocol

\begin{tabular}{ll}
\hline Initial dose & $\mathbf{1 0} \mathbf{~ m g / k g}$ weekly \\
\hline Dose increase [69] & $\begin{array}{l}\text { 3/4 of the dose every } 10 \text { days (after } 2 \text { successive successfully infusions) } \rightarrow \text { full } \\
\text { dose at a modified rate scheduled every } 2 \text { weeks } \rightarrow \text { standard recommended } \\
\text { rate } \\
\text { Initial concentration [72] }\end{array}$ \\
$\begin{array}{l}1 / 10,000-1 / 100 \text { of the full therapeutic dose. If anaphylaxis is severe: } \\
1 / 1,000,000-1 / 10,000 \text { of the full therapeutic dose. If positive skin test, the } \\
\text { starting dose can be determined based on the endpoint titration }\end{array}$ \\
Doubling or three-fold every $15-20$ min until the therapeutic dose is achieved
\end{tabular}

with micro dilutions, adjusting the dose/rate based on the patient's clinical manifestations and tolerance. In particular, protocols with a significant dose reduction should be avoided in patients with severe symptoms of the disease such as cardiomyopathy, as prognosis can be compromised in case of transient worsening. On the basis of the literature, a proposal of a desensitization protocol is reported in Table 7.

\section{Conclusions and future prospective}

Herein a summary of the evidence on adverse reactions to ERT in Pompe disease, particularly in its c-IOPD, is presented. Based upon our review of the available literature, we can conclude that there remains a need for the following.

- A novel approach to immune tolerance induction, especially protocols that are antigen-specific and/or more highly antigen targeted, rather than employing systemically immunosuppressive agents, in order to improve efficacy and safety.

- More personalized treatment approaches including immunogenicity prediction prior to ERT initiation, especially in CRIM positive patients.

- Further strategies for eliminating long-lived plasma cells.

- ERT Engineering to create non-immunogenic epitopes without reducing effectiveness.

In the future, gene therapy may play a relevant role by providing low doses of a non-toxic viral vector associated with ERT which could minimize the immune response.

\section{Acknowledgments}

We thank Genzyme Corp., which provided financial support for the meeting of the Experts Panel and for medical writing.

\section{Authors' contributions}

All authors equally contributed to the conception of the work, co-wrote the initial draft, critically reviewed the content and approved the final version of the work.

\section{Funding}

This research did not receive any specific grant from funding agencies in the public, commercial, or not-for-profit sectors.

\section{Declarations}

\section{Competing interests}

A.B.: was/is a member of Scientific Advisory Boards and received honoraria from Genzyme, Biomarin, Nutricia, APR, PIAM, Takeda, Recordati Rare Diseases; A.F.: financial support for University Research Grants by Sanofi-Genzyme; guest and travel expenses for National and International congresses by Takeda, Sanofi Genzyme and Biomarin; A.P.: none; C.C.: none; D.C.: none; F.D.: none; G.P.: none; G.S.: none; M.A. Donati: none; P.S.: none; R.D.C.: none; S.F.: none; S.G.: declares travel grants and consulting fees from Genzyme Sanofi; V.G.: none.

\section{Author details}

${ }^{1}$ Division of Inherited Metabolic Diseases - Department of Diagnostic Services, University Hospital of Padua, Padua, Italy. ${ }^{2}$ Department of Translational Medical Sciences, University of Naples Federico II, Naples, Italy. ${ }^{3}$ Unit of Metabolic Diseases, Ospedale Pediatrico Bambino Gesù, IRCCS|, Rome, Italy. ${ }^{4}$ Metabolic Rare diseases Unit - Pediatric Department, Fondazione MBBM, University of Milano-Bicocca, Monza, Italy. ${ }^{5}$ Metabolic and Neuromuscular Unit, Meyer Children Hospital-University of Florence, Florence, Italy. ${ }^{6}$ Division of Pediatric Immunology - Department of Health Sciences, Meyer Children HospitalUniversity of Florence, Florence, Italy. ${ }^{7}$ AORN Santobono Pausilipon, Naples, Italy. ${ }^{8}$ Pediatrics - Science of Health Department, University "Magna Graecia", Catanzaro, Italy. ${ }^{9}$ Telethon Institute of Genetics and Medicine, Naples, Italy.

${ }^{10}$ Regional Referral Centre for Metabolic Diseases (CRR-MET), UOC Pediatric Clinic - Department of Clinical and Experimental Medicine, University of Catania, Catania, Italy. ${ }^{11}$ Dipartimento Materno Infantile, A.O. San Pio, Benevento, Italy.

Received: 26 September 2021 Accepted: 22 January 2022

Published online: 05 March 2022

\section{References}

1. Reuser AJ, Hirschhorn R, Kors MA. Pompe disease: glycogen storage disease type II, acid a-glucosidase (acid maltase) deficiency; n.d.

2. Kishnani PS, Amartino HM, Lindberg C, Miller TM, Wilson A, Keutzer J, et al. Timing of diagnosis of patients with Pompe disease: data from the Pompe registry. Am J Med Genet A. 2013;161A:2431-43 https://doi.org/ 10.1002/ajmg.a.36110.

3. Kishnani PS, Hwu W-L, Mandel H, Nicolino M, Yong F, Corzo D, et al. A retrospective, multinational, multicenter study on the natural history of infantile-onset Pompe disease. J Pediatr. 2006;148:671-6 https://doi.org/ 10.1016/j.jpeds.2005.11.033.

4. van den Hout HMP, Hop W, van Diggelen OP, Smeitink JAM, Smit GPA, Poll-The B-TT, et al. The natural course of infantile Pompe's disease: 20 original cases compared with 133 cases from the literature. Pediatrics. 2003;112:332-40 https://doi.org/10.1542/peds.112.2.332.

5. Myozyme. Summary of Product Characteristics n.d.

6. Khan AA, Case LE, Herbert M, DeArmey S, Jones H, Crisp K, et al. Higher dosing of alglucosidase alfa improves outcomes in children with 
Pompe disease: a clinical study and review of the literature. Genet Med. 2020;22:898-907 https://doi.org/10.1038/s41436-019-0738-0.

7. Spada M, Pagliardini V, Ricci F, Biamino E, Mongini T, Porta F. Early higher dosage of alglucosidase alpha in classic Pompe disease. J Pediatr Endocrinol Metab. 2018;31:1343-7 https://doi.org/10.1515/jpem-2018-0336.

8. van Gelder CM, Poelman E, Plug I, Hoogeveen-Westerveld M, Van der Beek N A. ME, Reuser AJJ, et al. Effects of a higher dose of alglucosidase alfa on ventilator-free survival and motor outcome in classic infantile Pompe disease: an open-label single-center study. J Inherit Metab Dis 2016;39:383-390. https://doi.org/10.1007/s10545-015-9912-y.

9. Kishnani PS, Corzo D, Leslie ND, Gruskin D, Van der Ploeg A, Clancy JP, et al. Early treatment with alglucosidase alpha prolongs long-term survival of infants with Pompe disease. Pediatr Res. 2009;66:329-35 https:// doi.org/10.1203/PDR.0b013e3181b24e94.

10. Kishnani PS, Corzo D, Nicolino M, Byrne B, Mandel H, Hwu WL, et al. Recombinant human acid [alpha]-glucosidase: major clinical benefits in infantile-onset Pompe disease. Neurology. 2007;68:99-109 https://doi. org/10.1212/01.wnl.0000251268.41188.04.

11. Nicolino M, Byrne B, Wraith JE, Leslie N, Mandel H, Freyer DR, et al. Clinical outcomes after long-term treatment with alglucosidase alfa in infants and children with advanced Pompe disease. Genet Med. 2009;11:210-9 https://doi.org/10.1097/GIM.0b013e31819d0996.

12. Kishnani PS, Dickson PI, Muldowney L, Lee JJ, Rosenberg A, Abichandani $\mathrm{R}$, et al. Immune response to enzyme replacement therapies in lysosomal storage diseases and the role of immune tolerance induction. Mol Genet Metab. 2016;117:66-83 https://doi.org/10.1016/j.ymgme.2015.11.001.

13. Desai AK, Li C, Rosenberg AS, Kishnani PS. Immunological challenges and approaches to immunomodulation in Pompe disease: a literature review. Ann Transl Med. 2019;7:285. https://doi.org/10.21037/atm.2019.05.27.

14. Gallay L, Petiot P, Durieu I, Streichenberger N, Berard F. SWORD: a simplified desensitization protocol for enzyme replacement therapy in adult Pompe disease. Neuromuscul Disord. 2016;26:801-4 https://doi.org/10. 1016/j.nmd.2016.07.006.

15. Hunley TE, Corzo D, Dudek M, Kishnani P, Amalfitano A, Chen Y-T, et al. Nephrotic syndrome complicating alpha-glucosidase replacement therapy for Pompe disease. Pediatrics. 2004;114:e532-5 https://doi.org/ 10.1542/peds.2003-0988-L.

16. Banati M, Hosszu Z, Trauninger A, Szereday L, Illes Z. Enzyme replacement therapy induces T-cell responses in late-onset Pompe disease. Muscle Nerve. 2011:44:720-6 https://doi.org/10.1002/mus.22136.

17. Kazi ZB, Desai AK, Troxler RB, Kronn D, Packman S, Sabbadini M, et al. An immune tolerance approach using transient low-dose methotrexate in the ERT-nairve setting of patients treated with a therapeutic protein: experience in infantile-onset Pompe disease. Genet Med. 2019;21:887-95 https://doi.org/10.1038/s41436-018-0270-7.

18. Banugaria SG, Prater SN, Ng Y-K, Kobori JA, Finkel RS, Ladda RL, et al. The impact of antibodies on clinical outcomes in diseases treated with therapeutic protein: lessons learned from infantile Pompe disease. Genet Med. 2011;13:729-36 https://doi.org/10.1097/GIM.0b013e3182174703.

19. Abbott M-A, Prater SN, Banugaria SG, Richards SM, Young SP, Rosenberg AS, et al. Atypical immunologic response in a patient with CRIM-negative Pompe disease. Mol Genet Metab. 2011;104:583-6 https://doi.org/10. 1016/j.ymgme.2011.08.003.

20. Kishnani PS, Goldenberg PC, DeArmey SL, Heller J, Benjamin D, Young $\mathrm{S}$, et al. Cross-reactive immunologic material status affects treatment outcomes in Pompe disease infants. Mol Genet Metab. 2010;99:26-33 https://doi.org/10.1016/j.ymgme.2009.08.003.

21. Wang J, Lozier J, Johnson G, Kirshner S, Verthelyi D, Pariser A, et al. Neutralizing antibodies to therapeutic enzymes: considerations for testing, prevention and treatment. Nat Biotechnol. 2008;26:901-8 https://doi.org/ 10.1038/nbt.1484.

22. Broomfield A, Fletcher J, Davison J, Finnegan N, Fenton M, Chikermane $A$, et al. Response of 33 UK patients with infantile-onset Pompe disease to enzyme replacement therapy. J Inherit Metab Dis. 2016:39:261-71 https://doi.org/10.1007/s10545-015-9898-5.

23. Banugaria SG, Prater SN, Patel TT, Dearmey SM, Milleson C, Sheets KB, et al. Algorithm for the early diagnosis and treatment of patients with cross reactive immunologic material-negative classic infantile pompe disease: a step towards improving the efficacy of ERT. PLoS One. 2013;8:e67052 https://doi.org/10.1371/journal.pone.0067052.
24. Banugaria SG, Prater SN, McGann JK, Feldman JD, Tannenbaum JA, Bailey $C$, et al. Bortezomib in the rapid reduction of high sustained antibody titers in disorders treated with therapeutic protein: lessons learned from Pompe disease. Genet Med. 2013;15:123-31 https://doi.org/10.1038/gim. 2012.110.

25. Berrier KL, Kazi ZB, Prater SN, Bali DS, Goldstein J, Stefanescu MC, et al. CRIM-negative infantile Pompe disease: characterization of immune responses in patients treated with ERT monotherapy. Genet Med. 2015;17:912-8 https://doi.org/10.1038/gim.2015.6.

26. Lacaná E, Yao LP, Pariser AR, Rosenberg AS. The role of immune tolerance induction in restoration of the efficacy of ERT in Pompe disease. Am J Med Genet C Semin Med Genet. 2012;160C:30-9 https://doi.org/10.1002/ ajmg.c.31316.

27. van Gelder CM, Hoogeveen-Westerveld M, Kroos MA, Plug I, van der Ploeg AT, Reuser AJJ. Enzyme therapy and immune response in relation to CRIM status: the Dutch experience in classic infantile Pompe disease. J Inherit Metab Dis. 2015;38:305-14 https://doi.org/10.1007/ s10545-014-9707-6.

28. Parini R, De Lorenzo P, Dardis A, Burlina A, Cassio A, Cavarzere P, et al. Long term clinical history of an Italian cohort of infantile onset Pompe disease treated with enzyme replacement therapy. Orphanet J Rare Dis. 2018;13(1):32. https://doi.org/10.1186/s13023-018-0771-0.

29. Wang Z, Okamoto P, Keutzer J. A new assay for fast, reliable CRIM status determination in infantile-onset Pompe disease. Mol Genet Metab. 2014;111:92-100 https://doi.org/10.1016/j.ymgme.2013.08.010.

30. Bali DS, Goldstein JL, Rehder C, Kazi ZB, Berrier KL, Dai J, et al. Clinical laboratory experience of blood CRIM testing in infantile Pompe disease. Mol Genet Metab Rep. 2015;5:76-9 https://doi.org/10.1016/j.ymgmr.2015.10. 012.

31. Bali DS, Goldstein JL, Banugaria S, Dai J, Mackey J, Rehder C, et al. Predicting cross-reactive immunological material (CRIM) status in Pompe disease using GAA mutations: lessons learned from 10 years of clinical laboratory testing experience. Am J Med Genet C Semin Med Genet. 2012;160C:40-9 https://doi.org/10.1002/ajmg.c.31319.

32. Pompe disease GAA variant database n.d.

33. Prater SN, Banugaria SG, Morgan C, Sung CC, Rosenberg AS, Kishnani PS. Letter to the editors: concerning "CRIM-negative Pompe disease patients with satisfactory clinical outcomes on enzyme replacement therapy" by Al Khallaf et al. J Inherit Metab Dis. 2014;37:141-3 https://doi.org/10. 1007/s10545-013-9637-8.

34. Kazi ZB, Desai AK, Berrier KL, Troxler RB, Wang RY, Abdul-Rahman OA, et al. Sustained immune tolerance induction in enzyme replacement therapytreated CRIM-negative patients with infantile Pompe disease. JCl Insight. 2017;2 https://doi.org/10.1172/jci.insight.94328.

35. Messinger YH, Mendelsohn NJ, Rhead W, Dimmock D, Hershkovitz E, Champion M, et al. Successful immune tolerance induction to enzyme replacement therapy in CRIM-negative infantile Pompe disease. Genet Med. 2012;14:135-42 https://doi.org/10.1038/gim.2011.4.

36. Poelman $\mathrm{E}$, Hoogeveen-Westerveld M, Kroos-de Haan MA, van den Hout JMP, Bronsema KJ, van de Merbel NC, et al. High Sustained Antibody Titers in Patients with Classic Infantile Pompe Disease Following Immunomodulation at Start of Enzyme Replacement Therapy. J Pediatr 2018:195:236-243.e3. https://doi.org/10.1016/i.jpeds.2017.11.046.

37. Elder ME, Nayak S, Collins SW, Lawson LA, Kelley JS, Herzog RW, et al. B-Cell depletion and immunomodulation before initiation of enzyme replacement therapy blocks the immune response to acid alpha-glucosidase in infantile-onset Pompe disease. J Pediatr 2013;163:847-854.e1. https://doi.org/10.1016/j.jpeds.2013.03.002.

38. Desai AK, Baloh CH, Sleasman JW, Rosenberg AS and Kishnani PS. Benefits of prophylactic short-course immune tolerance induction in patients with infantile Pompe disease: demonstration of long-term safety and efficacy in an expanded cohort. 2020. Front Immunol 11:1727.

39. Schwab I, Nimmerjahn F. Intravenous immunoglobulin therapy: how does IgG modulate the immune system? Nat Rev Immunol. 2013;13:17689 https://doi.org/10.1038/nri3401.

40. Rezvani AR, Maloney DG. Rituximab resistance. Best Pract Res Clin Haematol. 2011;24:203-16 https://doi.org/10.1016/j.beha.2011.02.009.

41. Stenger EO, Kazi Z, Lisi E, Gambello MJ, Kishnani P. Immune tolerance strategies in siblings with infantile Pompe disease-advantages for a preemptive approach to high-sustained antibody titers. Mol Genet Metab Rep. 2015;4:30-4 https://doi.org/10.1016/j.ymgmr.2015.05.004. 
42. Li C, Desai AK, Gupta P, Dempsey K, Bhambhani V, Hopkin RJ, et al. Trans forming the clinical outcome in CRIM-negative infantile Pompe disease identified via newborn screening: the benefits of early treatment with enzyme replacement therapy and immune tolerance induction. Genet Med. 2021;23(5):845-55. https://doi.org/10.1038/s41436-020-01080-y.

43. Desai AK, Kazi ZB, Bali DS, Kishnani PS. Characterization of immune response in cross-reactive immunological material (CRIM)-positive infantile Pompe disease patients treated with enzyme replacement therapy. Mol Genet Metab Rep. 2019;20:100475 https://doi.org/10.1016/j.ymgmr. 2019.100475.

44. De Groot AS, Kazi ZB, Martin RF, Terry FE, Desai AK, Martin WD, et al. HLAand genotype-based risk assessment model to identify infantile onset pompe disease patients at high-risk of developing significant anti-drug antibodies (ADA). Clin Immunol. 2019;200:66-70 https://doi.org/10. 1016/j.clim.2019.01.009

45. Banugaria SG, Patel TT, Mackey J, Das S, Amalfitano A, Rosenberg AS, et al. Persistence of high sustained antibodies to enzyme replacement therapy despite extensive immunomodulatory therapy in an infant with Pompe disease: need for agents to target antibody-secreting plasma cells. Mol Genet Metab. 2012;105(4):677-80. https://doi.org/10.1016/j.ymgme.2012. 01.019 .

46. Mendelsohn NJ, Messinger YH, Rosenberg AS, Kishnani PS. Elimination of antibodies to recombinant enzyme in Pompe's disease. N Engl J Med. 2009;360:194-5 https://doi.org/10.1056/NEJMc0806809.

47. Kazi ZB, Prater SN, Kobori JA, Viskochil D, Bailey C, Gera R, et al. Durable and sustained immune tolerance to ERT in Pompe disease with entrenched immune responses. JCI Insight. 2016;1 https://doi.org/10. 1172/jci.insight.86821.

48. Poelman E, Hoogeveen-Westerveld M, van den Hout JMP, Bredius RGM, Lankester AC, Driessen GJA, et al. Effects of immunomodulation in classic infantile Pompe patients with high antibody titers. Orphanet J Rare Dis. 2019;14:71 https://doi.org/10.1186/s13023-019-1039-z.

49. Markic J, Polic B, Stricevic L, Metlicic V, Kuzmanic-Samija R, Kovacevic T, et al. Effects of immune modulation therapy in the first Croatian infant diagnosed with Pompe disease: a 3-year follow-up study. Wien Klin Wochenschr. 2014;126:133-7 https://doi.org/10.1007/s00508-013-0475-3.

50. Blasco-Alonso J, Gil-Gómez R, Jurado AL, Macías RY. Immunomodulation for Pompe disease with high sustained antibodies against enzyme replacement therapy. Med Clin (Barc). 2021;157(8):403-5. https://doi.org/ 10.1016/j.medcli.2020.09.017.

51. Owens P, Wong M, Bhattacharya K, Ellaway C. Infantile-onset Pompe disease: a case series highlighting early clinical features, spectrum of disease severity and treatment response. J Paediatr Child Health. 2018;54:125561 https://doi.org/10.1111/jpc.14070.

52. Deodato F, Ginocchio VM, Onofri A, Grutter G, Germani A, Dionisi-Vici C. Immune tolerance induced using plasma exchange and rituximab in an infantile Pompe disease patient. J Child Neurol. 2014;29:850-4 https://doi. org/10.1177/0883073813485819.

53. Rairikar M, Kazi ZB, Desai A, Walters C, Rosenberg A, Kishnani PS. High dose IVIG successfully reduces high rhGAA IgG antibody titers in a CRIM-negative infantile Pompe disease patient. Mol Genet Metab. 2017;122:76-9 https://doi.org/10.1016/j.ymgme.2017.05.006.

54. Ditters IAM, Huidekoper $\mathrm{HH}$, Kruijshaar ME, Rizopoulos D, Hahn A, Mongini TE, et al. European Pompe consortium project group on classic infantile Pompe disease. Effect of alglucosidase alfa dosage on survival and walking ability in patients with classic infantile Pompe disease: a multicentre observational cohort study from the European Pompe consortium. Lancet Child Adolesc Health. 2022;6(1):28-37. https://doi.org/10. 1016/S2352-4642(21)00308-4.

55. Neubert K, Meister S, Moser K, Weisel F, Maseda D, Amann K, et al. The proteasome inhibitor bortezomib depletes plasma cells and protects mice with lupus-like disease from nephritis. Nat Med. 2008;14:748-55 https://doi.org/10.1038/nm1763.

56. Lipinski SE, Lipinski MJ, Burnette A, Platts-Mills TA, Wilson WG. Desensitization of an adult patient with Pompe disease and a history of anaphylaxis to alglucosidase alfa. Mol Genet Metab. 2009;98:319-21 https://doi.org/ 10.1016/j.ymgme.2009.07.001

57. Hall PD. Immunomodulation with intravenous immunoglobulin. Pharmacotherapy. 1993;13:564-73.

58. Perez EE, Orange JS, Bonilla F, Chinen J, Chinn IK, Dorsey M, et al. Update on the use of immunoglobulin in human disease: a review of evidence. J
Allergy Clin Immunol. 2017;139:S1-46 https://doi.org/10.1016/j.jaci.2016. 09.023.

59. Orbach H, Katz U, Sherer $Y$, Shoenfeld Y. Intravenous immunoglobulin: adverse effects and safe administration. Clin Rev Allergy Immunol. 2005;29:173-84 https://doi.org/10.1385/CRIAl:29:3:173.

60. Doerfler PA, Nayak S, Corti M, Morel L, Herzog RW, Byrne BJ. Targeted approaches to induce immune tolerance for Pompe disease therapy. Mol Ther Methods Clin Dev. 2016;3:15053 https://doi.org/10.1038/mtm.2015. 53.

61. Joly MS, Martin RP, Mitra-Kaushik S, Phillips L, D'Angona A, Richards SM, et al. Transient low-dose methotrexate generates $B$ regulatory cells that mediate antigen-specific tolerance to alglucosidase alfa. J Immunol. 2014;193:3947-58 https://doi.org/10.4049/jimmunol.1303326.

62. Banugaria SG, Patel TT, Kishnani PS. Immune modulation in Pompe disease treated with enzyme replacement therapy. Expert Rev Clin Immunol. 2012;8:497-9 https://doi.org/10.1586/eci.12.40.

63. Battaglia M, Stabilini A, Roncarolo M-G. Rapamycin selectively expands CD4+CD25+FoxP3+ regulatory T cells. Blood. 2005;105:4743-8 https:// doi.org/10.1182/blood-2004-10-3932.

64. Biswas M, Sarkar D, Kumar SRP, Nayak S, Rogers GL, Markusic DM, et al. Synergy between rapamycin and FLT3 ligand enhances plasmacytoid dendritic cell-dependent induction of CD4+CD25+FoxP3+ Treg. Blood. 2015;125:2937-47 https://doi.org/10.1182/blood-2014-09-599266.

65. Gerriets VA, Rathmell JC. Metabolic pathways in T cell fate and function. Trends Immunol. 2012;33:168-73 https://doi.org/10.1016/j.it.2012.01.010.

66. Nayak S, Cao O, Hoffman BE, Cooper M, Zhou S, Atkinson MA, et al. Prophylactic immune tolerance induced by changing the ratio of antigenspecific effector to regulatory T cells. J Thromb Haemost. 2009;7:1523-32 https://doi.org/10.1111/j.1538-7836.2009.03548.x.

67. Sarkar D, Biswas M, Liao G, Seay HR, Perrin GQ, Markusic DM, et al. Ex vivo expanded autologous polyclonal regulatory T cells suppress inhibitor formation in hemophilia. Mol Ther Methods Clin Dev. 2014;1 https://doi. org/10.1038/mtm.2014.30.

68. Lim J-A, Li L, Shirihai OS, Trudeau KM, Puertollano R, Raben N. Modulation of mTOR signaling as a strategy for the treatment of Pompe disease. EMBO Mol Med. 2017;9:353-70. https://doi.org/10.15252/emmm.20160 6547.

69. El-Gharbawy AH, Mackey J, DeArmey S, Westby G, Grinnell SG, Malovrh P, et al. An individually, modified approach to desensitize infants and young children with Pompe disease, and significant reactions to alglucosidase alfa infusions. Mol Genet Metab. 2011;104:118-22 https://doi.org/10. 1016/j.ymgme.2011.07.004.

70. Burton BK, Whiteman DAH, Investigators HOS. Incidence and timing of infusion-related reactions in patients with mucopolysaccharidosis type II (hunter syndrome) on idursulfase therapy in the real-world setting: a perspective from the hunter outcome survey (HOS). Mol Genet Metab. 2011;103:113-20 https://doi.org/10.1016/j.ymgme.2011.02.018.

71. Atanaskovic-Markovic M, Gomes E, Cernadas JR, du Toit G, Kidon M, Kuyucu S, et al. Diagnosis and management of drug-induced anaphylaxis in children: an EAACI position paper. Pediatr Allergy Immunol. 2019;30:26976 https://doi.org/10.1111/pai.13034.

72. Cernadas JR, Brockow K, Romano A, Aberer W, Torres MJ, Bircher A, et al. General considerations on rapid desensitization for drug hypersensitivity - a consensus statement. Allergy. 2010;65:1357-66 https://doi.org/10. 1111/j.1398-9995.2010.02441.x.

73. Demoly P, Adkinson NF, Brockow K, Castells M, Chiriac AM, Greenberger PA, et al. International consensus on drug allergy. Allergy. 2014;69:420-37 https://doi.org/10.1111/all.12350.

74. Toh TSW, Chong KW, Goh AEN, Goh JCY, Ting TW, Tan ES, et al. Enzyme replacement therapy desensitization in a child with infantile onset Pompe disease. Asian Pac J Allergy Immunol. 2020. https://doi.org/10. 12932/AP-060919-0638.

75. Baruteau J, Broomfield A, Crook V, Finnegan N, Harvey K, Burke D, et al. Successful desensitisation in a patient with CRIM-positive infantile-onset Pompe disease. JIMD Rep. 2014;12:99-102 https://doi.org/10.1007/8904_ 2013_250.

76. Amalfitano A, Bengur AR, Morse RP, Majure JM, Case LE, Veerling DL, et al. Recombinant human acid alpha-glucosidase enzyme therapy for infantile glycogen storage disease type II: results of a phase I/II clinical trial. Genet Med. 2001;3:132-8. https://doi.org/10.109700125817-20010 3000-00007. 
77. Kishnani PS, Nicolino M, Voit T, Rogers RC, Tsai AC-H, Waterson J, et al. Chinese hamster ovary cell-derived recombinant human acid alphaglucosidase in infantile-onset Pompe disease. J Pediatr. 2006;149:89-97 https://doi.org/10.1016/j.jpeds.2006.02.035.

78. van der Ploeg AT, Clemens PR, Corzo D, Escolar DM, Florence J, Groeneveld GJ, et al. A randomized study of alglucosidase alfa in late-onset Pompe's disease. N Engl J Med. 2010;362:1396-406 https://doi.org/10 1056/NEJMoa0909859.

79. Gragnaniello V, Fecarotta S, Pecoraro A, Tarallo A, Catzola A, Spadaro $G$, et al. Desensitization of two young patients with infantile-onset Pompe disease and severe reactions to alglucosidase alfa. Neurol Sci. 2019;40:1453-5 https://doi.org/10.1007/s10072-019-03744-3.

80. Rohrbach M, Klein A, Köhli-Wiesner A, Veraguth D, Scheer I, Balmer C, et al. CRIM-negative infantile Pompe disease: 42 -month treatment outcome. J Inherit Metab Dis. 2010;33:751-7 https://doi.org/10.1007/ s10545-010-9209-0.

81. Capanoglu M, Dibek Misirlioglu E, Azkur D, Vezir E, Guvenir H, Gunduz M, et al. IgE-mediated hypersensitivity and desensitisation with recombinant enzymes in Pompe disease and type I and type VI Mucopolysaccharidosis. Int Arch Allergy Immunol. 2016;169:198-202 https://doi.org/10.1159/ 000446154

82. Karagol IHE, Bakirtas A, Yilmaz O, Topal E, Kucukcongar A, Ezgu FS, et al. Desensitisation of the youngest patient with Pompe disease in response to alglucosidase alfa. Allergol Immunopathol (Madr). 2014;42:372-5 https://doi.org/10.1016/j.aller.2013.02.012.

83. Emecen Sanli M, Ertoy Karagol HI, Kilic A, Aktasoglu E, Inci A, Okur I, et al. First successful concomitant therapy of immune tolerance induction therapy and desensitization in a CRIM-negative infantile Pompe patient. J Pediatr Endocrinol Metab. 2021. https://doi.org/10.1515/jpem-2021-0133.

\section{Publisher's Note}

Springer Nature remains neutral with regard to jurisdictional claims in published maps and institutional affiliations.

- fast, convenient online submission

- thorough peer review by experienced researchers in your field

- rapid publication on acceptance

- support for research data, including large and complex data types

- gold Open Access which fosters wider collaboration and increased citations

- maximum visibility for your research: over 100M website views per year

At BMC, research is always in progress.

Learn more biomedcentral.com/submissions 